\title{
ESTRUTURA ORGANIZACIONAL E INTERNACIONALIZAÇÃO DE EMPRESAS: UM ESTUDO DE CASO NO SETOR SUCROENERGÉTICO DO BRASIL
}

\author{
ORGANIZATIONAL STRUCTURE AND THE INTERNATIONALIZATION OF \\ COMPANIES: A CASE STUDY IN BRAZIL'S SUGAR AND ALCOHOL SECTOR
}

\section{ESTRUCTURA ORGANIZACIONAL E INTERNACIONALIZACIÓN DE EMPRESAS: UN ESTUDIO DE CASO EN EL SETOR SUCROENERGÉTICO DE BRASIL}

\author{
Marina Carrilho Soares \\ Mestranda em Administração da Faculdade de Economia, Administração e Contabilidade da \\ Universidade de São Paulo - FEA/USP \\ E-mail: marina.soares@usp.br (Brasil)
}

\section{Heidy Rodriguez Ramos}

Doutora em Administração da Faculdade de Economia, Administração e Contabilidade da Universidade de São Paulo - FEA/USP

Professora da Fundação Instituto de Administração - FIA

E-mail: heidy@usp.br (Brasil)

\section{Maria Soledad Etchebarne}

Doutora em Administração e Gestão de Marketing pela Universidad de Sevilla, Espanha

Professora da Universidade Diego Portales - UDP

E-mail: setchebarne@udp.cl (Chile)

\section{Valeska Geldres}

Doutora em Administração e Gestão de Marketing pela Universidad de Sevilla, Espanha Professora da Universidade de La Frontera - UFRO

E-mail: vgeldres@ufro.cl (Chile) 


\title{
ESTRUTURA ORGANIZACIONAL E INTERNACIONALIZAÇÃO DE EMPRESAS: UM ESTUDO DE CASO NO SETOR SUCROENERGÉTICO DO BRASIL
}

\section{RESUMO}

No atual cenário de acelerada globalização, destaca-se o caso do setor sucroenergético do Brasil, que, por ser bastante desregulamentado, tem recebido investimentos estrangeiros consideráveis, principalmente motivado pela grande demanda internacional pelo etanol e pela competitividade do produto nacional. Entretanto, mesmo que o setor apresente boas perspectivas, as empresas devem possuir uma estratégia consistente em seu mercado externo, além de um plano de internacionalização sólido. Utilizando a metodologia do estudo de caso na Companhia Brasileira de Energia Renovável - Brenco, buscou-se, por meio desse trabalho descrever a estrutura organizacional de uma empresa do setor sucroalcooleiro do Brasil, considerada um novo empreendimento internacional. Essa investigação teve como objetivo de identificar a existência de um novo modelo de negócio inovador nesse setor, caracterizado por grandes grupos de empresas locais, direcionadas para o mercado interno. Entre os principais resultados obtidos, constatou-se que a estrutura organizacional está alinhada com o objetivo de ser uma empresa internacional, com a meta de tornar-se uma das cinco maiores empresas desse setor até 2015. Em razão disso, pode se afirmar que a organização desenvolveu um modelo de negócio único e inovador nesse setor.

Palavras-chave: Estrutura Organizacional; Internacionalização; Setor Sucroenergético.

\section{ORGANIZATIONAL STRUCTURE AND THE INTERNATIONALIZATION OF COMPANIES: A CASE STUDY IN BRAZIL'S SUGAR AND ALCOHOL SECTOR}

\begin{abstract}
In today's scenario of accelerated globalization, an outstanding case is that of Brazil's sugar and alcohol sector which, quite deregulated, has received considerable foreign investment motivated by the large global demand for ethanol as a source of fuel and by the competitive quality of the domestic product. It is important to underline that even when this sector shows good prospects, these enterprises should have a consistent strategy to enter the world markets with a solid internationalization plan. By using the Case Study Methodology at Brenco, the Brazilian Renewable Energy Company, this paper sought to outline the organization chart of this entity, regarded as an international project, with the aim of identifying the existence of an advanced innovative business model within this sector, characterized by large groups of local enterprises, directed toward the domestic market. Among the main results obtained it is notable that the organization chart is in line with the goal of being a global enterprise and with the target of becoming, by 2015, one of the sector's five largest enterprises.
\end{abstract}

Keywords: Internationalization; Organization Chart; Sugar and Alcohol Sector.

Revista Ibero-Americana de Estratégia - RIAE, São Paulo, v. 10, n. 3, p. 49-65, set./dez. 2011. 
Marina Carrilho Soares, Heidy Rodriguez Ramos, Maria Soledad Etchebarne \& Valeska Geldres

ESTRUCTURA ORGANIZACIONAL E INTERNACIONALIZACIÓN DE EMPRESAS:

UN ESTUDIO DE CASO EN EL SETOR SUCROENERGÉTICO DE BRASIL

\section{RESUMEN}

En el actual contexto de acelerada globalización, se destaca el caso del sector sucroenergético de Brasil que, por ser bastante desregulado, ha recibido considerables inversiones extranjeras, principalmente motivado por la gran demanda internacional por el etanol y por la competitividad de este producto nacional. Sin embargo, aún cuando el sector presenta buenas perspectivas, las empresas deben poseer una estrategia consistente en su mercado externo, además de un plan de internacionalización sólido. Utilizando la metodología del estudio de caso, se buscó, por medio de este trabajo, describir la estructura organizacional de una empresa del sector sucroenergético de Brasil, considerada un nuevo emprendimiento internacional. Esta investigación tuvo como objetivo identificar la existencia de un nuevo modelo de negocio innovador en este sector, caracterizado por grandes grupos de empresas locales, dirigidos al mercado interno. Entre los principales resultados obtenidos, se constató que la estructura organizacional está alineada con el objetivo de ser de una empresa internacional, con la meta de ser una de las cinco mayores empresas de este sector hasta 2015. En razón de ello, se puede afirmar que la organización desarrolló un modelo de negocio único e innovador en este sector.

Palabras-clave: Estructura Organizacional; Internacionalización; Sector Sucroenergético.

Revista Ibero-Americana de Estratégia - RIAE, São Paulo, v. 10, n. 3, p. 49-65, set./dez. 2011. 
Estrutura Organizacional e Internacionalização de Empresas: Um Estudo de Caso no Setor Sucroenergético do Brasil

\section{INTRODUÇÃO}

A atual economia mundial, caracterizada pela formação de blocos econômicos e uma maior abertura entre os países, vem obrigando organizações a estar em sintonia com os acontecimentos globais, operando independentemente de suas fronteiras nacionais. Assim, teorias têm sido formuladas para estudar o tema da internacionalização de organizações durante o último século. Nesse sentido, muitas empresas têm tentado ampliar sua participação internacional, o que exige adaptações em suas estruturas internas para que essa estratégia seja perseguida, de modo eficiente e eficaz.

Nesse cenário, observa-se o caso do setor sucroenergético do Brasil, que, bastante desregulamentado, tem recebido investimentos estrangeiros consideráveis, devido, principalmente, à grande demanda internacional pelo álcool carburante e à competitividade do produto nacional. Uma tendência de expansão desse setor tem sido observada nos últimos anos, pelo aumento significativo no número de usinas em operação.

Entretanto, essas empresas devem possuir uma estratégia consistente em seu mercado externo, além de um plano de internacionalização sólido. Para isso, as organizações devem saber ajustar sua estrutura a esses planos, de maneira que não haja desperdício de esforços ao longo do caminho. Portanto, o objetivo da atual pesquisa é descrever a estrutura organizacional de uma empresa que atua nesse setor, considerada como um empreendimento internacional, visando identificar a existência de um novo modelo de negócio inovador num setor caracterizado por grandes grupos de empresas locais, direcionadas para o mercado interno.

\section{REFERENCIAL TEÓRICO}

\subsection{INTERNACIONALIZAÇÃO}

O conceito de internacionalização está relacionado à decisão de investir em certo mercado de destino das exportações para ampliar e fortalecer as vendas nesse local, segundo Iglesias e Veiga (2002). Uma empresa internacional é aquela que possui estabelecimentos comerciais afiliados que operam, simultaneamente, em outros países, ou, ainda, como uma sociedade que desenvolve suas atividades (produção, comercialização e serviços) em outro país, diverso que sua matriz está situada (Meinerz,1999).

Revista Ibero-Americana de Estratégia - RIAE, São Paulo, v. 10, n. 3, p. 49-65, set./dez. 2011. 
Tal qual mencionado anteriormente, existem algumas abordagens em administração e em economia que tratam do processo de internacionalização de empresas. A abordagem econômica, cujo principal expoente consiste na teoria eclética da internacionalização desenvolvida por John Dunning, aplica os conceitos de custos de transação para explicar as características das empresas e seus mercados, que podem funcionar como estímulos à internacionalização, havendo três tipos de vantagens para as empresas: de localização, de propriedade e de internalização (Dunning, 1980).

Outra perspectiva que trata da internacionalização de empresas é a que aborda o tema sob o ponto de vista de administração e negócios. Com relação a essa última perspectiva, observam-se, principalmente, as escolas denominadas comportamentalistas, que tratam o processo de internacionalização como gradual, evolutivo, e com foco principal nas razões e características desse gradualismo. Uma linha importante desses conceitos é a escola nórdica de Uppsala, cujos principais autores são Vahlne e Johanson, que visualiza o processo de internacionalização como gradual, uma vez que existem diferenças culturais e distâncias psicológicas entre os países de origem e os mercados dos países-alvo.

Essas diferenças acabam por gerar incertezas com relação aos resultados a serem atingidos, de modo que a única maneira de minimizá-las seria por meio do conhecimento da outra cultura, no decorrer do tempo, e com o aumento da experiência da empresa. Dessa forma, a internacionalização possuiria duas características fundamentais que incluem o conhecimento do mercado e o comprometimento de recursos, sendo que para atingir o sucesso a organização deve se engajar em atividades que lhes permita explorar esses dois pontos. (Johanson, Vahlne, 1977).

Com relação aos tipos de entrada em países estrangeiros, se destaca a exportação como um meio bastante comum, principalmente no início da expansão internacional da companhia. Esse modo de entrada pode ser classificado, ainda em três grupos: a exportação indireta, a cooperativa e a direta. Existem ainda outras formas de entrada em um mercado estrangeiro. Elas incluem estratégias de licenciamento, o franchising e, por fim, os chamados contratos de produção. Essas formas permitem um ingresso no mercado de destino com um volume menor de investimentos comprometidos, embora não permitam fluxos de renda volumosos (Kotabe, Helsen, 2000).

Com um comprometimento maior de recursos, existem também as chamadas joint-ventures, nas quais uma empresa estrangeira concorda em compartilhar capital e demais recursos com outros sócios, sendo estabelecida uma nova entidade no país-alvo. É também comum que muitas empresas multinacionais optem por estratégias de propriedade que podem ser tanto de empresas locais pelas multinacionais ou operações completas, também chamadas de greenfield, que devem ocorrer quando as aquisições não se mostram viáveis e as empresas optam, então, por iniciar a operação do

Revista Ibero-Americana de Estratégia - RIAE, São Paulo, v. 10, n. 3, p. 49-65, set./dez. 2011. 
Estrutura Organizacional e Internacionalização de Empresas: Um Estudo de Caso no Setor Sucroenergético do Brasil

zero. O controle acionário também é uma estratégia de internacionalização que envolve grande comprometimento de recursos, mas permite controles maiores sobre as operações.

Há que se considerar, ainda, o recente fenômeno das empresas chamadas born globals, que são concebidas, desde o início, com perfil explicitamente internacional. Esses novos empreendimentos internacionais contrariam os padrões evolutivos de internacionalização, defendidos pela abordagem comportamental. As empresas que seguem essa teoria são negócios que, desde sua concepção, procuram desenvolver vantagens competitivas a partir do uso de recursos e das oportunidades de vendas em outros países (Oviatt, Mcdougall, 1994).

Ainda, segundo esses autores, o foco não está no porte da empresa, e sim na idade quando ela torna-se internacional. O diferencial de tais empreendimentos é, de fato, sua orientação internacional inata, que pode ser demonstrada pelo comprometimento de recursos em mais de uma nação, ou ao menos a intenção de fazê-lo, nos casos em que o produto ou serviço da companhia ainda esteja em desenvolvimento. O enfoque teórico dos autores descreve quatro elementos que são necessários para a existência dos international new ventures (INVs), novos negócios internacionais sustentáveis: 1) internalização de algumas transações; 2) estruturas alternativas de governança; 3) vantagens de localização; 4) controle de recursos únicos. Em seguida, elabora-se uma tipologia que designa quatro tipos diferentes de INV, considerando-se o número de atividades dentro da cadeia de valores que são coordenadas por eles, em um eixo, e, no outro, o número de países em que estão inseridos.

\subsection{ESTRUTURA ORGANIZACIONAL}

A estrutura organizacional é definida, segundo Morais (2004), como um arranjo dos elementos constitutivos de uma organização. Segundo esse autor, é a forma mediante a qual estão integrados e se apresentam os elementos componentes de uma empresa. Também pode ser identificada como o conjunto das diferentes maneiras como essa organização divide e coordena seu trabalho em tarefas (Mintzberg, 1979).

A estrutura também pode ser definida como o resultado de um processo por meio do qual a autoridade é atribuída, as atividades são especificadas, desde os níveis mais baixos até os mais altos, e um sistema de comunicação também é delineado, possibilitando que as pessoas realizem seus trabalhos e exerçam a autoridade atribuída, de modo que os objetivos organizacionais sejam alcançados. A partir dessa definição, se propõe o delineamento de uma estrutura que considere os vários fatores que devem interagir, com os seguintes desenhos: estrutura departamentalizada, que

Revista Ibero-Americana de Estratégia - RIAE, São Paulo, v. 10, n. 3, p. 49-65, set./dez. 2011. 
significa um agrupamento de indivíduos e equipamentos, cujos espaços são delimitados por critérios funcionais, geográficos, por processos ou por clientes, por produtos, período de tempo e amplitude de controle. Ainda pode ser configurada uma estrutura com áreas de apoio, sendo essas centralizadas ou não, compartilhando, assim, serviços em comum com as diferentes áreas; por fim, áreas de assessoria, em casos específicos que exijam suporte adicional dessas áreas (Vasconcellos; Hemsley, 2002).

Daft (1998) destaca que existem alguns tipos de estrutura que são classicamente delineados pelos principais autores. O primeiro tipo é a estrutura funcional, que possui como características a divisão das atividades da empresa de acordo com habilidades, especialidades e utilização de recursos similares. Esse tipo de departamentalização apresenta algumas vantagens para a organização, como a utilização eficiente de recursos, especialização maior, possibilidades de crescimento na carreira para os indivíduos dentro dos departamentos, controle e direção da alta administração e melhor coordenação dentro das funções. Por outro lado, essa estrutura padece de uma comunicação precária entre os diferentes departamentos, além de concentrar as decisões apenas no topo da hierarquia e apresentar dificuldades em se localizar, de maneira precisa, a responsabilidade dos problemas.

Outras abordagens de departamentalização são propostas, como a abordagem divisional, segundo a qual os departamentos são agrupados com base no resultado da organização, e divisões autossuficientes são formadas para criar um único produto. Uma terceira forma de departamentalização é a abordagem matricial, que utiliza, simultaneamente, a cadeia de comando funcional e por divisões na mesma parte da organização, existindo duas linhas de autoridade, sendo uma estrutura frequentemente utilizada em empresas globais (Daft, 1998).

Com relação à ligação entre a estrutura de uma empresa e sua estratégia, Almeida, Neto e Giraldi (2006) foram os primeiros a apontar tal relacionamento, que se constitui de maneira dinâmica, havendo uma relação de interdependência entre o ambiente externo, a estratégia e a estrutura. Segundo esse autor, a estrutura mais adequada é aquela que está vinculada à estratégia da organização, desde o desenho da estrutura até as atividades-chave e os recursos estruturais. Além disso, as decisões estratégicas são aquelas que têm por objetivo a distribuição, no longo prazo, dos recursos existentes e o desenvolvimento de novos e essenciais recursos, como forma de garantir o crescimento saudável da empresa no futuro.

Segundo esses autores, quando há a necessidade de se mudar a estratégia de uma organização, também é necessário que haja mudanças no modo pelo qual ela está estruturada. Isso ocorre, uma vez que a estrutura acaba definindo a maneira pela qual os objetivos e políticas serão

Revista Ibero-Americana de Estratégia - RIAE, São Paulo, v. 10, n. 3, p. 49-65, set./dez. 2011. 
Estrutura Organizacional e Internacionalização de Empresas: Um Estudo de Caso no Setor Sucroenergético do Brasil

estabelecidos e recursos serão alocados, portanto, não há um desenho de estrutura ótimo para uma dada estratégia ou tipo de organização.

\section{METODOLOGIA}

A pesquisa desenvolvida se caracteriza por ser do tipo qualitativa. Com relação à sua classificação, o estudo foi exploratório e descritivo, já que, por um lado, buscou-se descrever a estrutura organizacional da empresa objeto de estudo, assim como suas estratégias de internacionalização. Por outro, se observou em que medida o modelo de negócio adotado pela empresa é inovador, dadas as características do setor.

Além disso, esse trabalho consiste em um estudo de caso. A escolha do caso (empresa Brenco) foi feita com base em entrevistas realizadas ao Sr. Artur Milanez, analista do Departamento de Biocombustíveis do Banco e ao Sr. Luciano Rodrigues, analista econômico-financeiro da União da Indústria de Cana-de-açúcar (Unica), por meio de conversas via telefone e correio eletrônico ao primeiro, e uma entrevista pessoal ao segundo. Também foram consultados dados secundários, obtidos a partir de pesquisa bibliográfica em periódicos, anais de congressos, informativos corporativos e endereços eletrônicos para a composição do referencial teórico do trabalho e identificação do caso.

Para a obtenção das informações sobre a empresa, de modo que fosse possível realizar a análise, foi entrevistado o Sr. Rogério Manso, vice-presidente comercial e de logística da organização. A entrevista foi realizada pessoalmente, com a aplicação de um roteiro de entrevistas semiestruturado.

\section{A EMPRESA}

A Brenco- Companhia Brasileira de Energia Renovável - iniciou suas operações no início do ano de 2007 e está implantando um projeto, em escala mundial, para a produção de biocombustíveis, destinado ao mercado doméstico e internacional, por meio de projetos de greenfield. O etanol da cana-de-açúcar é o principal produto da empresa, e sua produção deverá estar pronta para a comercialização em meados de 2009. A empresa busca se tornar referência mundial em energia renovável e estar entre as 5 maiores empresas desse setor até 2015, atuando de

Revista Ibero-Americana de Estratégia - RIAE, São Paulo, v. 10, n. 3, p. 49-65, set./dez. 2011. 
acordo com três grandes pilares, a saber, custo (para que se consiga chegar ao mercado consumidor a um preço competitivo), confiabilidade (para que se consiga entregar o produto de acordo com as especificações negociadas) e sustentabilidade (da produção à distribuição).

Para concretizar esses objetivos a Brenco deverá investir cerca de R \$ 5,5 bilhões na construção de pólos bioenergéticos, com um total de 10 unidades industriais, que contribuirão para atingir a meta de 1 bilhão de galões de etanol por ano, volume esse que até 2015 deverá representar cerca de $10 \%$ da produção nacional e $5 \%$ da produção mundial desse combustível. Em razão da grandeza dos investimentos e dos seus projetos, a empresa busca se inserir nesse segmento não apenas a produção do combustível, mas, também, a comercialização e distribuição do produto, atuando, de maneira integrada, para desenvolver o mercado do etanol não apenas internamente, mas, também, em escala internacional (Brenco, 2009a).

Com relação às questões produtivas, a companhia vem investindo no cultivo da cana-deaçúcar em pólos agroindustriais, com plantas detentoras de tecnologia de ponta. Entre seus objetivos, está o de possuir unidades em três pólos bioenergéticos com, ao menos, duas unidades cada, em um raio de 100 quilômetros, na região Centro-Oesse brasileira.

Deve-se deixar bastante claro que, ao contrário da grande parte das empresas do setor sucroalcooleiro do Brasil, a Brenco não produzirá açúcar, o que deverá proporcionar uma maior eficiência tanto operacional quanto logística, em razão do grau de automação permitido por esse foco no etanol e especialização em um único produto. Além da produção de etanol, a empresa também visa à geração de energia renovável que deve ser consumida por suas unidades produtoras, vendendo o excedente previsto, uma vez que a não-existência de uma refinaria de açúcar reduz o consumo de energia e vapor (Brenco, 2009b).

Com relação à sua estratégia de constituição de pólos produtivos, convém explicar que essa alternativa, combinada com a produção de etanol como único produto da empresa, contribui para ganhos de escala significativos, não apenas na produção, permitindo que os custos fixos sejam diluídos e posicionando a organização como um dos maiores produtores desse combustível, mas, também, ganhos de escala na aquisição de equipamentos e construção de novas unidades e no escoamento do produto.

Atualmente a empresa opera em dois desses pólos: Alto Taquari- Mineiros e Paranaíba. No primeiro, a empresa está construindo cinco novas unidades, que estarão localizadas nos municípios de Mineiros e Perolândia, no Estado de Goiás, e Alto Taquari, no Estado do Mato Grosso. Já no segundo pólo, há três unidades, localizadas nos municípios de Paranaíba e Costa Rica, no Estado do Mato Grosso do Sul, e na cidade de Itajá, em Minas Gerais.

Revista Ibero-Americana de Estratégia - RIAE, São Paulo, v. 10, n. 3, p. 49-65, set./dez. 2011. 
Estrutura Organizacional e Internacionalização de Empresas: Um Estudo de Caso no Setor Sucroenergético do Brasil

Um último ponto a destacar é a questão da comercialização e da estratégia logística da empresa. Com relação à integração vertical, a empresa controla todos os ativos envolvidos em sua cadeia produtiva, desde a plantação até a distribuição e comercialização. Conforme enfatizado pelo Sr. Rogério Manso, esse controle não ocorre necessariamente com a posse dos ativos específicos envolvidos ao longo da cadeia, mas é necessário para que se garanta o atendimento dos critérios de custo, confiabilidade e sustentabilidade.

\subsection{ESTRUTURA ORGANIZACIONAL}

No organograma da empresa, representado na figura 1, as áreas de maior importância para o negócio são: a logística, a área de comercialização e as áreas agroindustriais. É importante ressaltar a escolha de profissionais que vêm atuando na área energética, com experiência internacional prévia, algo que pode ser considerado bastante valioso na empresa em questão, além de apontar a ênfase dada às áreas de logística, comercialização e de operações agroindustriais da empresa.

Figura 1 - Organograma da Brenco.

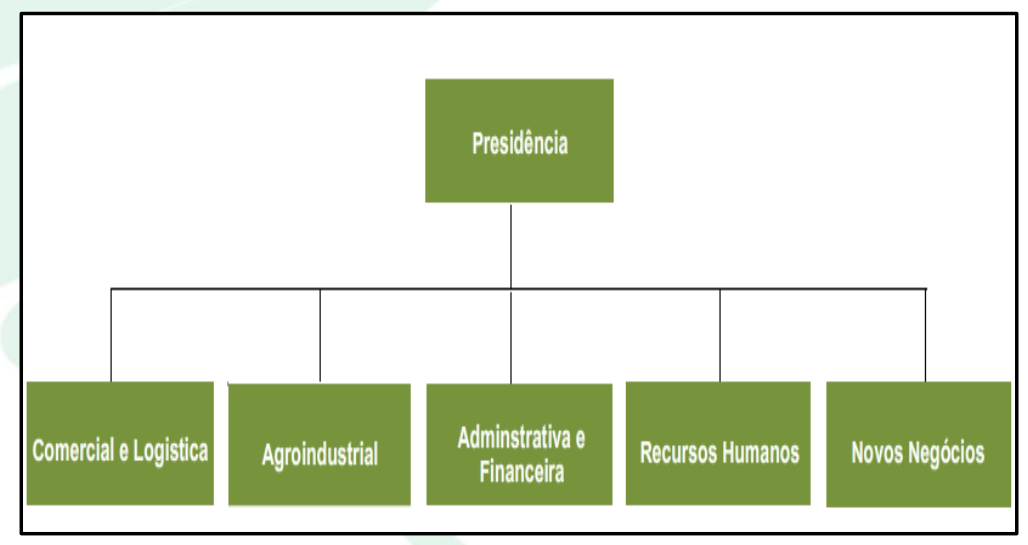

A Brenco surgiu da união de um conjunto de investidores nacionais e internacionais que ingressaram nos negócios do etanol, isto é, grandes grupos do mercado financeiro que se uniram para entrar nesta indústria. Henri Phillipe Reichstul, presidente da empresa, foi o principal responsável pela estruturação da diretoria executiva do grupo. Além disso, mesmo não sendo uma companhia de capital aberto, a Brenco está estruturada como tal, possuindo um conselho de administração integrado por profissionais com experiência no mercado de capital e representantes dos principais investidores. Ainda, os investimentos do grupo estão relacionados a projetos de

Revista Ibero-Americana de Estratégia - RIAE, São Paulo, v. 10, n. 3, p. 49-65, set./dez. 2011. 
greenfield, que partem do zero, e estão localizados na principal área de expansão das atividades sucroalcooleiras, a região Centro-Oeste do País (Neto, 2008).

Segundo Ieda (2007), a estruturação em pólos produtivos permite a maximização de sinergias administrativas e operacionais, além de possibilitar maior eficiência na implantação das unidades industriais e ganhos de escala em logística no escoamento da produção, além de permitir maior controle no abastecimento de matérias-primas. As plantas em questão são construídas a partir de projetos de greenfield, o que permite a construção de unidades com condições operacionais superiores às tradicionais, além de permitir a maximização da eficiência da operação agroindustrial desde a concepção do projeto, até a exploração de regiões com custos fundiários menores do que regiões tradicionais e que tenham foco total no etanol, evitando, também a herança de passivos ambientais e trabalhistas.

Todos esses pontos devem permitir à Brenco a maior escala de produção do Brasil, e, dessa forma, a empresa deve tornar-se uma das maiores exportadoras de etanol do mundo. A Brenco atua na produção, distribuição e comercialização, com base em expectativas de comoditização do etanol. Caso esse fato venha a se consolidar, será exigida uma estrutura totalmente verticalizada dos produtores tradicionais. A Brenco vem antecipando esses aspectos e, dessa forma, possui o controle de todos os ativos específicos necessários a atender essas três dimensões. Mesmo que não tenha a posse do ativo, a empresa possui estruturas de governança capazes de lhe garantir o controle, segundo o entrevistado.

Além de se conseguir baixos custos, por meio da escala de produção propiciada pela estrutura planejada, os projetos logísticos da empresa devem propiciar custos reduzidos de transporte e transmitir confiabilidade. Comparando-se as diversas opções logísticas, concluiu-se que a forma de transporte dutoviária apresentava vantagens significativas de custo e nos quesitos qualidade, segurança, meio ambiente e saúde. Dessa forma, a empresa optou pela construção do próprio duto para escoamento de sua produção e de terceiros, garantindo não apenas as questões de custos, mas, também, questões relacionadas à confiabilidade (Ieda, 2007).

\subsection{ESTRATÉGIAS}

A missão da Brenco é "produzir e fornecer globalmente energia renovável com sustentabilidade e excelência operacional". Entre seus valores corporativos, estão incluídos aqueles que prezam pela segurança das pessoas, pela sustentabilidade e compromisso com a sociedade e com o resultado e inovação. Desta forma, a empresa investe em atividades de pesquisa e melhorias que possam beneficiar seu processo produtivo e a forma como faz seus negócios, incluindo as áreas

Revista Ibero-Americana de Estratégia - RIAE, São Paulo, v. 10, n. 3, p. 49-65, set./dez. 2011. 
Estrutura Organizacional e Internacionalização de Empresas: Um Estudo de Caso no Setor Sucroenergético do Brasil

de engenharia genética de novas variedades de cana-de-açúcar, novas técnicas de plantio, mecanização da colheita, novos processos de moagem e destilação e fontes novas ou aprimoradas do etanol, como o celulósico, por exemplo. Seguindo esses princípios, a visão da empresa é ser referência mundial em energia renovável e estar entre as maiores do setor até 2015 (Brenco, 2009c).

Segundo o Sr. Rogério Manso, a companhia possui perfil explicitamente internacional, tanto que as primeiras safras da empresa prevêem que dois terços da produção devem ser destinados aos mercados externos. Ainda, o entrevistado destacou que, embora o etanol seja amplamente exportado, essa exportação é “oportunista”, ocorrendo em momentos em que o mercado sinaliza positivamente ao combustível e, assim, as principais usinas exportadoras apenas reagem a esses sinais. Este não deve ser o caso da Brenco, uma vez que sua estratégia é internacional desde sua fundação e, assim, todas suas ações estão orientadas para dar suporte a esse plano.

Neste aspecto, a estratégia internacional, segundo o entrevistado, é o grande diferencial da empresa em relação ao setor. Ao ser perguntado por que, em sua opinião, a empresa estaria nascendo com esse perfil de atendimento ao mercado externo, quando existe um mercado interno significativo, a pessoa consultada afirmou que esse último já é plenamente abastecido pelos produtores atuais, e adotar uma postura similar seria "mais do mesmo". Assim, a proposta da Brenco é implementar um novo modelo de negócios para esse setor, o que favorece a abertura do mercado internacional de etanol, contando, para isso, com um quadro de gerentes e diretores que possuem experiência em internacionalização.

Segundo o entrevistado, uma das principais barreiras para a entrada do etanol em outros países é a tarifária, uma vez que todos os locais de destino possuem sistemas tributários que inviabilizam uma maior penetração do etanol como combustível. Outras questões que se colocam como obstáculos a uma maior abertura do mercado internacional ao produto são as questões que se referem a certificações do etanol. Outro dificultador é a questão da logística no Brasil.

Para contornar essas barreiras, a Brenco escolheu o sistema dutoviário para escoar sua produção do Centro-Oeste brasileiro para os portos na região Sudesse. Assim, sua estratégia logística inclui a construção de um duto que liga seus pólos produtivos nos estados centrais brasileiros até os principais portos.

Revista Ibero-Americana de Estratégia - RIAE, São Paulo, v. 10, n. 3, p. 49-65, set./dez. 2011. 


\section{ANÁLISE DOS RESULTADOS}

Primeiramente, cabe dizer que a Brenco constitui uma empresa nascida global, considerando-se sua estratégia inicial de focar, principalmente, no mercado internacional. Isso é comprovado ao observar os comentários do entrevistado e a intenção clara de exportar dois terços de sua produção, assim que estiver pronta para a comercialização. Enquanto isso não ocorre, a empresa já atua como uma trading, comercializando a produção de terceiros.

Além disso, a empresa apresenta as quatro características estabelecidas pelos autores Oviatt e McDougall (1994), que permitem caracterizá-la como um novo empreendimento internacional: possui uma estrutura verticalmente integrada, com a internalização de certas atividades; usufrui de vantagens de localização significativas; possui uma estrutura alternativa de governança, que inclui a integração vertical e outras formas que permitem garantir o controle de seus ativos principais; e, por fim, tem a posse de ativos específicos únicos e necessários à sua operação e consecução da estratégia.

Por outro lado, todas suas ações que visam à configuração de sua estrutura, levam em consideração o plano de tornar-se uma das cinco maiores empresas desse setor até 2015. De acordo com o Sr. Rogério Manso, a estrutura organizacional da Brenco segue sua estratégia, de maneira a apoiá-la. Isso pode ser comprovado ao analisar as ações que a empresa vem adotando, envolvendo as questões com relação à escolha entre produção ou compra de ativos de terceiros, e mesmo à composição de seu quadro de gerentes e diretores.

Atendendo aos requisitos de custo, confiabilidade e sustentabilidade, todos os aspectos que vão desde a configuração do organograma da empresa, escolha da equipe executiva, construção das próprias plantas, ao invés de comprar unidades já existentes, construção do próprio sistema dutoviário e estruturação das operações em pólos produtivos estão alinhados a esses três grandes pilares que norteiam as ações da empresa.

Observa-se claramente a intenção de se utilizar da exportação direta como maneira de inserir o produto no mercado internacional. A ação adotada para acompanhar essa estratégia foi a construção do próprio duto para transportar a produção de suas plantas até os principais portos do país. Tal estratégia ainda contribui para contornar um dos principais problemas enfrentados pelos produtores do setor sucroalcooleiro no momento de exportar o etanol, que é o gargalo logístico.

A estratégia logística escolhida também está alinhada com os três pilares que norteiam as ações da empresa. O sistema dutoviário, atualmente, é visto como a melhor alternativa ao transporte e distribuição de etanol, uma vez que contribui para a redução de custos e a diminuição de gases de efeito estufa.

Revista Ibero-Americana de Estratégia - RIAE, São Paulo, v. 10, n. 3, p. 49-65, set./dez. 2011. 
Estrutura Organizacional e Internacionalização de Empresas: Um Estudo de Caso no Setor Sucroenergético do Brasil

A estratégia de formação de pólos energéticos permite ainda a manutenção de preços a níveis baixos, maximização de sinergias e eficiência na implantação das unidades agroindustriais, além de ganhos logísticos no escoamento da produção. Com relação aos projetos de greenfield, observa-se que a empresa tem todos seus projetos focados na construção de novas unidades, partindo do zero.

Conforme mencionado no item sobre a estrutura da empresa, os projetos de greenfield surgem para garantir à organização condições operacionais superiores às plantas usuais, permitindo uma maior eficiência da operação agroindustrial, a exploração de regiões com custos menores do que as tradicionais, além de se evitar a herança de passivos ambientais, trabalhistas e fiscais. Essa estratégia, juntamente com a decisão de se produzir exclusivamente o etanol, ao invés de se combinar a produção desse combustível com a do açúcar, como é comum entre os produtores tradicionais, deve permitir à empresa, ganhos significativos de escala em relação a outras empresas, tornando-a uma das maiores exportadoras do mundo.

Por fim, com relação ao seu organograma, este apresenta uma divisão funcional ao separar departamentos específicos (como o de logística, operações agroindustriais, administrativo e financeiro, recursos humanos e novos negócios). Esta opção deve garantir à empresa vantagens como o agrupamento de pessoas com habilidades e especialidades afins, além de permitir o uso mais eficiente de recursos e economias de escala dentro dos departamentos.

\section{CONSIDERAÇÕES FINAIS}

A pesquisa foi iniciada propondo a descrição da estrutura organizacional de uma empresa do setor sucroalcooleiro do Brasil, procurando analisar a coerência de suas estratégias por meio de um estudo descritivo e exploratório. De fato, após uma breve apresentação da plataforma teórica do estudo, foram descritas as principais características tanto da estrutura da empresa, quanto de suas principais estratégias para a consecução de seus objetivos, fazendo-se um balanço.

Comparando-se esses dois pontos, foi possível concluir que a estrutura organizacional desta empresa específica dá suporte, de fato, às suas estratégias principais. Pode-se compreender que os três grandes pilares que fazem parte da estratégia da empresa são atendidos em todos os aspectos observados. Custo, confiabilidade e sustentabilidade estão presentes desde as decisões sobre a organização das operações em pólos agroindustriais e construção do próprio sistema logístico, até as

Revista Ibero-Americana de Estratégia - RIAE, São Paulo, v. 10, n. 3, p. 49-65, set./dez. 2011. 
decisões sobre a integração vertical das atividades e construção de projetos de greenfield voltados para a produção de etanol.

Entretanto, segundo o profissional entrevistado, devido ao atual momento de crise econômica, a empresa deve adotar algumas medidas que permitam tornar sua estrutura um pouco mais enxuta, considerando-se o ambiente externo. Feita essa ressalva, pode-se dizer que tais medidas não afetam a estratégia inicial da empresa, mas incluem apenas determinados aspectos de adaptação à situação atual.

Os elementos apresentados ao longo da pesquisa mostram que a empresa estudada se configurou de maneira bastante diferente dos outros grupos sucroalcooleiros tradicionais, o que ressalta seu modelo de negócios inovador.

Existem alguns pontos que devem ser ressaltados, embora não contrariem os aspectos mencionados anteriormente. Considera-se como principal limitação o fato de que a pesquisa abordou um estudo de caso único, não podendo ser considerado representativo para fazer generalizações. Não obstante, sugere-se para pesquisas posteriores investigar casos similares de empresas consideradas como empreendimentos internacionais, para analisar se sua estrutura está de acordo com suas estratégias.

\section{REFERÊNCIAS}

Almeida, F.C., Neto, A.J.M., Giraldi, J.M.E.(abril/junho de 2006) Estrutura e estratégia: evolução de paradigmas. Revista de Gestão USP, 13( 2),15-26.

Brenco (2009a). Gerando energia limpa com sustentabilidade - Um projeto de escala mundial. Recuperado em maio 2009, de: http://www.brenco.com.br/brenco/Historia.aspx.

Brenco (2009b). Foco em energia renovável. Recuperado em maio 2009, de http://www.brenco.com.br/brenco/Vmm.aspx.

Brenco (2009c). Valores Brenco. Recuperado em maio 2009, de: http://www.brenco.com.br/brenco/Valoresbrenco.aspx.

Daft, R. L.(1998) Administração. Rio de Janeiro: LTC.

Dunning, J. H.(1980) Toward an eclectic theory of international production: some empirical tests. Journal of Business Studies, 11(1), 9-31.

http://dx.doi.org/10.1057/palgrave.jibs.8490593

Revista Ibero-Americana de Estratégia - RIAE, São Paulo, v. 10, n. 3, p. 49-65, set./dez. 2011. 
Estrutura Organizacional e Internacionalização de Empresas: Um Estudo de Caso no Setor Sucroenergético do Brasil

Ieda, E.( 7 e 8 de Novembro de 2007) Reinventando a usina modelo de negócios Brenco. In: Actas de Congresso Brasileiro Agroindustrial ( $\left.8^{\circ} \mathrm{CBA}\right)$.

Iglesias, R. M., Veiga, P. M.(2002) Promoção das exportações via internacionalização das firmas de capital brasileiro. In: BNDES. O desafio das exportações. Rio de Janeiro.

Johanson, J., Vahlne, J. E. (1977) The internationalization process of the firm- a model of knowledge development and increasing foreign market commitments. Journal of International Business Studies. 8(1).

http://dx.doi.org/10.1057/palgrave.jibs.8490676

Kotabe, M., Helsen, K.(2000) Administração de marketing global. São Paulo: Atlas.

Meinerz, P. R. (1999) Risco e retorno na internacionalização: o caso das empresas brasileiras no Mercosul. Dissertação de Mestrado, Faculdade de Economia, Administração e Contabilidade, Universidade de São Paulo. São Paulo, SP, Brasil.

Mintzberg, H. (1979) The structuring of organizations: a synthesis of the research. New Jersey: Prentice-Hall.

Morais, J. M.(2004) Estrutura organizacional na empresa familiar - Estilos gerenciais e satisfação dos funcionários. Dissertação de Mestrado em Gestão e Desenvolvimento Regional, Universidade de Taubaté, São Paulo, Brasil.

Neto, M. M. (2008) Setor sucroalcooleiro e espaço financeiro: a construção do mercado de bioenergia. Recuperado em maio 2009, de : http://www.dep.ufscar.br/grupos/nesefi/st/anais_st/eixoI/Martin.pdf.

Oviatt, B.M., Mcdougall, P.P. Toward a theory of international new ventures. Journal of International Business Studies, n.25, p. 45-64, Março 1994.

Vasconcellos, E., Hemsley, J. R.(2002) Estrutura das organizações: estruturas tradicionais, estruturas para inovação, estrutura matricial. São Paulo: Pioneira Thomson Learning.

Revista Ibero-Americana de Estratégia - RIAE, São Paulo, v. 10, n. 3, p. 49-65, set./dez. 2011. 
Recebido: 06/10/2011

Aprovado: 30/11/2011

Revista Ibero-Americana de Estratégia - RIAE, São Paulo, v. 10, n. 3, p. 49-65, set./dez. 2011. 